\title{
The Influence of Retail Outlet and FSMA Information on Consumer Perceptions of and Willingness to Pay for Organic Grape Tomatoes
}

\author{
Ellison, Brenna ${ }^{\mathrm{a}}$; Bernard, John C. ; Paukett, Michelle ${ }^{\mathrm{b}}$; Toensmeyer, Ulrich C. ${ }^{\mathrm{b}}$
}

${ }^{a}$ Agricultural and Consumer Economics, University of Illinois at Urbana-Champaign, $1301 \mathrm{~W}$. Gregory Dr., Urbana, IL, 61801, USA, brennae@ illinois.edu (Corresponding author)

${ }^{b}$ Applied Economics and Statistics, University of Delaware, 531 South College Ave., Newark, DE, 19716, USA 


\begin{abstract}
:
The primary objective of this research was to determine the effect of retail outlet (supercenter, supermarket, farmers market, fresh format) on consumer perceptions of and willingness to pay (WTP) for organic grape tomatoes. Also examined was whether information on the proposed Food Safety Modernization Act (FSMA) regulations, with and without information on tomato safety, altered these aspects across retail outlets. Field experiments were conducted with 207 participants in two U.S. states in fall 2014 to address these questions. Consumers' perceptions and WTP varied significantly by retail outlet, with farmers markets and fresh format stores receiving the most favorable evaluations and supercenters the least. With FSMA information, safety perceptions fell significantly for the favored outlets and mostly increased for supercenters. Participants' felt no producers should be exempt from the FSMA and viewed farmers markets vendors as most likely to be exempt. Unexpectedly though, these changes seldom translated into changes in WTP. Further, in treatments with added tomato safety information, supercenters saw no safety rating benefit. Overall, it was clear the organic label was not viewed equally across different retail outlets.
\end{abstract}

Keywords:

Organic

Willingness to pay

Retail outlet

Food Safety Modernization Act

Field experiment

JEL Classification:

D12 (Consumer Economics: Empirical Analysis)

Q13 (Agricultural Markets and Marketing; Cooperatives; Agribusiness)

PsycINFO Classification:

2229 (Consumer Opinion \& Attitude Testing)

3920 (Consumer Attitudes \& Behavior)

3940 (Marketing \& Advertising) 


\section{Introduction}

Not long ago, the primary purveyors of organic food were relatively small natural food stores, leaving interested consumers with few choices in retail outlets. As organic food became more popular, though, the options for purchasing locations began to grow. With the passage of the National Organic Program (NOP) in 2002 creating uniform USDA standards, the industry has grown tremendously in terms of size and product scope (ERS, 2014). The list of grocery outlets offering organic alternatives now includes supermarkets and major retailers such as Walmart, Target, and Aldi (Wohl, 2014; Tuttle, 2013; Ewoldt, 2013). These newer venues compete for organic food sales with such seemingly disparate outlets as Whole Foods and Natural Grocers as well as more local farmers markets, food co-ops, and community supported agriculture (CSAs).

The rise in the organic food market has led to several studies on consumer perceptions and willingness to pay (WTP) for such foods. These consistently show a higher WTP for organic foods over their conventional counterparts (for a review see Rödiger and Hamm, 2015), with reasons for interest in them ranging from personal concerns including health, safety and taste to those regarding the environment and animal welfare (for a review on motivations for organic purchases, see Hughner et al., 2007). These studies, however, typically treat organic with the unstated assumption that an organic food purchased from one outlet is no different from one purchased at another outlet. Typically though, due to elements such as differences in economies of scale and store images, consumers will not pay the same price for organics at different venues. For example, organic food at a fresh format store will likely sell at a higher price point than at a supercenter, but it is currently unclear what this means for consumer perceptions and WTP. Worstall (2014) contends that for some consumers, organic foods may function as a Veblen good such that the organic good's higher price is a clear signal of the good's higher quality. Thus, by low-cost retailers offering organics at lower price points they may be inadvertently informing consumers they are of lower quality. Such differing views based on venue, if they exist, suggest that asking about consumers' interest in organic food generally may be suboptimal and lead to potentially misleading conclusions. Specifically it remains to be seen whether consumers perceive organic products to be comparable across different retail outlets. 
To date there have been few studies that consider purchasing venue to some extent in relation to organic purchases. In France, Ngobo and Jean (2012) found that a low-price store image decreased the rate of private-label organic purchases. In the U.S., Onken, Bernard, and Pesek (2011) found that consumers were willing to pay more for strawberry preserves sold at a farmers market compared to a grocery store. Further, within the same category of store (supercenters), Ellison et al. (2016) found that a more hedonic retailer like Target may be better for promoting organic vice products (such as cookies) whereas a more functional retailer like Walmart may have more success promoting organic virtue products (such as strawberries). While these studies provide some initial evidence that the retail outlet (venue) has an impact on preferences, this will be the first study, to the researchers' knowledge, to compare consumer perceptions and WTP of an organic product across a broad spectrum of retail outlets, which more accurately reflects today's organic market.

Concurrent with the growth of the organic market, interest in food safety has increased. The Centers for Disease Control and Prevention (CDC) estimates that one in six Americans (approximately 48 million people) get sick every year from foodborne illnesses, leading to 128,000 hospitalizations and 3,000 deaths (CDC, 2014). Further, since 2010, there has been an average of 11.6 multistate foodborne outbreak investigations per year with the majority of these investigations for fruits and vegetables, meats, and dairy products (CDC, 2015).

Research has also shown consumers place a high value on the safety of the food they consume. Lusk and Briggeman (2009) found that safety is the most important food value (relative to taste, nutrition, price, etc.) to U.S. consumers. Similarly, Ellison and Lusk (2011) found that U.S. consumers would like to see more USDA budget dollars allocated toward food safety relative to other budget segments. Additionally, research has found consumers were willing to pay more for products with enhanced food safety attributes (Angulo and Gil, 2007; Loureiro and Umberger, 2007; McCluskey et al., 2005; Enneking, 2004; Boccaletti and Nardella, 2000; Baker, 1999; Latouche, Rainelli, and Vermersch, 1998 Henson, 1996; Misra, Huang, and Ott, 1991), though it should be noted the WTP premiums for food safety are often small in magnitude (less than 10\%). Which food safety attributes are studied, however, varies by the product in question. Several studies have focused on food safety attributes related to beef in light of the bovine spongiform encephalopathy (BSE) scares (Angulo and Gil, 2007; Loureiro and Umberger, 2007; McCluskey et al., 2005; Latouche, Rainelli, and Vermersch, 1998). However, 
there are also studies that consider food safety attributes (e.g., pesticide-free) for produce (Misra, Huang, and Ott, 1991; Boccaletti and Nardella, 2000). Further, research suggests that consumers often ascribe enhanced safety benefits with other credence attributes such as organic (Hughner et al., 2007), non-GMO (Costa-Font, Gil, and Traill, 2008), and country-of-origin labeling (Lusk et al, 2006), so valuation studies of these attributes may also be partially identifying consumers' valuation of food safety.

In response to food safety concerns in the U.S., President Obama signed the Food Safety Modernization Act (FSMA) into law in 2011. The act represents the first reform to food safety laws in over 70 years and shifts the focus to attempts to prevent contamination rather than responding to outbreaks (FDA, 2015a). Under FSMA, there are seven proposed rules related to various aspects of food safety, including preventive controls for human and animal food, sanitary transportation, foreign supplier verification programs, food safety audits, intentional adulteration, and produce safety. To date, five of the seven rules have been finalized; the remaining two rules (related to sanitary transportation and intentional adulteration) are expected to be released in spring 2016 (FDA, 2015b).

The FSMA rules will impact organic and conventional producers, processors, and manufacturers alike. There are, however, differences based on operation size. Small and medium-sized operations have expressed concerns over potential costs of implementation (Satran, 2012) for which the Food and Drug Administration (FDA) has provided a number of exemptions to ensure the guidelines can be implemented by farms regardless of size (Satran, 2013; FDA, 2015c). The two key exemptions under the produce rule relating to size considerations (based on sales) are: 1) Farms that have an average annual value of produce ${ }^{1}$ sold during the previous three-year period of $\$ 25,000$ or less, and 2) Farms that have food sales averaging less than $\$ 500,000$ per year during the last three years and the farm's sales to qualified end-users (final consumer or restaurant/retail food establishment that is located in the same state as the farm or less than 275 miles away) must exceed sales to others ${ }^{2}$ (FDA, 2015c).

\footnotetext{
${ }^{1}$ Under the originally proposed rule, the FDA proposed that the value of food (not produce) sold during the previous three-year period must be $\$ 25,000$ or less in order to be exempt (FDA, 2013). At the time of this study, the final rule had not been released; thus, our information treatments reflect the exemption language from the proposed rule.

${ }^{2}$ Farms which meet these two requirements would be eligible for a qualified exemption and would be subject to modified requirements (FDA, 2015c).
} 
For consumers concerned about food safety, the key takeaway is that the majority of produce sold in the U.S. will be subject to the new FSMA regulations, which should ideally reduce the number of foodborne illnesses. However, the exemptions provided by the FDA indicate that smaller farms, or farms which primarily sell to end consumers, will not be subject to the more stringent requirements. Depending on consumers' knowledge and preferences for food safety, these exemptions could shift purchases away from these smaller operations and toward larger retailers who likely source their produce from larger operations which can meet their volume demands and are subject to the FSMA regulations. In terms of specific venues, this could possibly a) reduce consumer interest and WTP for organic produce from farmers markets which are important outlets for small and medium-sized producers who are more likely to qualify for an exemption, and b) improve consumers' view of organic produce from supercenters. Unfortunately, little is currently known in regard to consumers' knowledge of the proposed FSMA rules and how this knowledge may shape safety perceptions and purchasing behavior within and across retail outlets. One purpose of this research was therefore to provide insight on this current gap in the literature.

Specifically, this paper examines two key issues: (1) whether and how consumer perceptions of, and WTP for, organic grape tomatoes vary across four categories of retail outlets (farmers market, fresh format, supermarket, and supercenter); and (2) how information on the proposed FSMA regulations impacts safety perceptions and WTP for organic grape tomatoes within and across these retail outlets. Part of this included determining if an added statement regarding issues with tomato food safety would alter the influence of the FSMA regulations. As the statement noted outbreaks traced to tomatoes have been more prevalent in the Eastern U.S., analysis was planned to see if there were any differences between results from a Midwestern state (Illinois) and an Eastern state (Delaware).

Organic grape tomatoes were selected for this research for a number of reasons. First, they were widely available (and in season) across the desired retail outlets in both locations over the course of the experiment. Secondly, grape tomatoes are a product many consumers are familiar with and purchase, allowing for a broader population from which to sample. Finally, tomatoes were known to be a source of several foodborne illnesses (primarily Salmonella outbreaks) in the past, so this was a product where information on the proposed FSMA rules may be more relevant in the minds of consumers and details of outbreaks could be presented. 


\section{Data and Methods}

\subsection{Participants and Recruitment}

The research was conducted through use of field experiments. Field experiments provide some important advantages over more traditional lab experiments. Lusk and Fox (2003) note that field experiments allow researchers to better examine the population of interest, thus decreasing sample selection bias. Further, field experiments facilitate data collection in a more natural setting (Lusk and Fox, 2003; Harrison and List, 2004).

Individuals were recruited in two U.S. states, Illinois and Delaware, between August and October, 2014 to participate in brief (10 minutes or less) sessions on organic grape tomatoes. Both sites used convenience sampling at a variety of locations, including local parks (8.7\% of total observations), supermarkets (16.9\%), farmers markets (15.5\%), and college campuses (58.9\%). For the latter, it is important to note that the research teams in both states collected data from on-campus restaurants ( $30 \%$ of total sample) which were open to the general public, leaving a smaller sample from areas more heavily frequented by undergraduate students (29\% of total sample). The only eligibility criteria were that participants had to be at least 18 years of age and a consumer of tomatoes. For participating in the study, individuals were paid five dollars (\$5). In total, 219 individuals participated in the study. Twelve responses were removed from the sample due to incomplete surveys, leaving a total of 207 observations. The sample was relatively evenly split between the states, with 98 participants from Delaware and 109 from Illinois. ${ }^{3}$

\subsection{Experimental Design}

Upon consenting to participate in the study, each session began with a Becker-DeGrootMarschak (BDM) mechanism (Becker, DeGroot, and Marschak, 1964) to elicit WTP for a pint (16 ounces) of organic grape tomatoes from the four different retail locations (supercenter, supermarket, fresh format, and farmers market). No brand information was provided. Participants were informed that all tomatoes were USDA certified organic and an empty pint package (all labeling removed) was available on-site for any participants who may have been unfamiliar with or unsure of the package size they were bidding on. The four venues were

\footnotetext{
${ }^{3}$ A power calculation was conducted to affirm the sample was sufficient for the multiple planned comparisons.
} 
selected because they represent a broad spectrum of retail outlets where consumers may shop for organic produce, particularly grape tomatoes. Throughout the study, each retail outlet was referred to by its store class level (supermarket, supercenter, etc.) with location-specific examples of each type of retail store provided in parentheses. ${ }^{4}$ With the exception of the farmers market location, at least two store examples were provided to participants for each retail outlet to encourage participants to make decisions at the store class level rather than on an individual store's reputation. ${ }^{5}$

The BDM elicitation mechanism was used because it is incentive compatible (in other words, it encourages individuals to bid truthfully; Lusk, Feldkamp, and Schroeder, 2004) and, unlike experimental auctions, can be run with a single person. For the BDM, participants were asked to submit bids on all four versions simultaneously that reflected how much they would be willing to pay for each product. To control for order effects, four versions of the bid sheets were printed where the four products were listed in different orders. ${ }^{6}$ None of the products were visible to avoid participants bidding based on sensory characteristics. It was explained that even though participants were placing bids on multiple products, only one product would actually be sold and this would be drawn at random along with the binding price later in the session. Participants were given a description of the workings of the BDM mechanism and advised that it was in their best interest to submit a bid equal to the price they were actually willing to pay for the product. In the BDM procedure, participants have no incentive to understate their true WTP because the binding price is determined by a random draw, not the participant's bid. If a participant bids higher than her true value, she could end up paying a price higher than her true value. Conversely, if a subject bids lower than her true value, she could miss out on a profitable

\footnotetext{
${ }^{4}$ For the retail outlets, we used standard industry terminology (see The Future of Food Retailing industry report published by Willard Bishop at http://www.iddba.org/pdfs/wis/The-Future-of-Food-Retailing-2015.pdf). This report provides formal definitions for each retail outlet type; however, we felt giving participants location-specific examples would be more helpful in terms of understanding the differences between retail outlets.

${ }^{5}$ Supermarket examples were ACME and Shoprite in Delaware and Schnucks and County Market in Illinois; fresh format examples were Whole Foods and Fresh Market in Delaware and Whole Foods and Common Ground Food Co-op in Illinois. Walmart and Target were the examples for supercenters in both states.

${ }^{6}$ All data was collected via a paper-and-pencil survey instrument. For a full copy of the instrument used, please refer to the appendix.
} 
purchase. ${ }^{7}$ Bids were restricted to fall between $\$ 0$ and $\$ 5$ to ensure participants' incentives could cover any purchase costs.

After the first round of bidding, participants were asked to complete a brief survey regarding their perceptions of the four pints of organic grape tomatoes. For each retail outlet, participants rated the perceived safety, health, and taste of the organic grape tomatoes using a 7point scale where $1=$ Not very safe (not very healthy, tastes very bad) and $7=$ Very safe (very healthy, tastes very good). Participants also rated their confidence that the grape tomatoes labeled as organic were truly organic for each retail outlet (also measured with a 7-point scale where $1=$ No confidence and $7=$ Complete confidence). Finally, participants indicated their level of knowledge on a 7 -point scale ( $1=$ Not very knowledgeable, $7=$ Very knowledgeable) on four topics: FSMA, organic, tomato safety, and Salmonella.

In the next portion of the study, participants were systematically assigned to one of two information treatments. Both information treatments gave some basic facts about the proposed FSMA regulations, including the objective of FSMA, basic requirements for food facilities, and the two exemption rules related to farm size described previously. This information was primarily derived from public-facing documents published by the FDA. In the second information treatment, participants also received information specifically related to tomato safety. This consisted of a quote from the FDA about the number of multistate outbreaks attributed to the contamination of raw tomatoes and the resulting number of illnesses and deaths. The quote noted a higher incidence of tomato outbreaks in the Eastern U.S., allowing the potential for its impact to be greater in Delaware than in the Illinois sample. For the second information treatment, the researchers systematically randomized the order of information across participants (e.g., some received FSMA information first then the tomato safety quote, others vice versa); however, no differences were detected between the two groups. A sample information treatment is provided in figure 1.

Upon reading the fact sheet, participants were given the opportunity to ask any questions about the information. Then, participants were asked to bid again on the four pints of organic grape tomatoes. Participants were reminded of the nature of the BDM mechanism and encouraged to submit a bid equal to their true value for each product. Once the second round of

\footnotetext{
${ }^{7}$ For more on the BDM mechanism, refer to Becker, DeGroot, and Marschak,1964; Corrigan and Rousu, 2008; Thrasher et al., 2011.
} 
bidding was complete, the researchers randomly drew which round/retail outlet combination (out of eight possible) would be binding along with the binding price. The binding price was randomly drawn from a uniform distribution which ranged from $\$ 0.25$ to $\$ 5.00$ in increments of $\$ 0.25$. If the individual bid more than the price drawn, he/she paid the binding price out of their $\$ 5$ participation money and received the appropriate pint of organic grape tomatoes. Once the BDM procedure was complete, participants were asked to fill out a second brief questionnaire, which consisted of two distinct sections. In the first section, participants were asked to state their level of agreement/disagreement (using a 5-point scale where 1=Strongly disagree and 5=Strongly agree) with five statements related to attitudes toward food safety and FSMA. They were also asked to rate the perceived safety of the organic grape tomatoes sold in each of the retail outlets for a second time to determine whether the information provided altered safety perceptions. In addition, participants rated the likelihood (on a 7-point scale where $1=$ Very unlikely and $7=$ Very likely) that each of the retail outlets was selling organic grape tomatoes that would be exempt from FSMA. The last section of the questionnaire asked about socio-demographic and behavioral characteristics, including gender, age, income, education, presence of children in the home, frequency of organic produce purchases, and frequency of purchasing produce at each of the four types of retail outlets.

\subsection{Data Analysis}

The first objective of this study was to provide insight on whether and how consumers' perceptions of and WTP for organic grape tomatoes vary across retail outlets. These measures were analyzed using repeated measures analysis of variance (ANOVA) with Bonferroni corrections for multiple comparisons. In each of the repeated measures ANOVA models, we control for gender, age, income, education, and state. The second objective of the study was to determine how information on the proposed FSMA regulations, with or without the accompanying tomato safety quote, affects safety ratings and WTP for organic grape tomatoes within and across retail outlets. As these variables were non-normally distributed, this analysis was performed using the Wilcoxon signed rank test on the pre- and post-information perceived safety ratings and WTP bids. This analysis was conducted at the state level, as we expected the prevalence of tomato safety outbreaks in the Eastern U.S. to differentially impact WTP and safety ratings for the Delaware participants. 


\section{Results}

\subsection{Sample Characteristics}

Table 1 provides the demographic profile for the participants in this study. As can be seen from the table, our sample was $68.1 \%$ female and relatively well educated (approximately $70 \%$ with a bachelor's degree or higher). The average age was 38.2 years with an average annual household income of $\$ 70,400$. As mentioned, there was a fairly even split of participants in each of the geographical regions. In terms of purchasing behaviors, table 1 shows that a majority of our respondents (57.7\%) buy organic produce "Sometimes", with supermarkets and farmers markets being the most common venues for buying produce.

When comparing respondents across the two states, the samples were quite comparable with the exception of two variables. First, respondents in Delaware had a significantly higher income, on average, than respondents in Illinois. Second, Illinois participants shopped more frequently at supercenters compared to Delaware participants - a finding which is less surprising given the income difference between the two groups.

\subsection{Consumer Perceptions and Willingness to Pay across Retail Outlets}

The first objective of this paper was to determine whether and how perceptions of, and WTP for, organic grape tomatoes vary across retail outlets. Table 2 presents the average ratings for perceived safety, health, taste, and confidence in the organic label as well as the average WTP values before food safety information was provided. This isolates the effect of retail outlet on each of the measures. For all five measures, the repeated measures ANOVA revealed a significant and strong store effect, even when controlling for socio-demographic variables such as gender, age, income, education, and state.

From the table, it is clear that respondents do not view a pint of organic grape tomatoes uniformly across retail outlets. Rather, there appears to be three distinct tiers. Organic grape tomatoes in the top tier are sold in fresh format stores or at farmers markets. With the exception

of perceived taste, there were no significant differences between ratings or WTP values for these two retail outlets. Participants expected organic grape tomatoes from these two outlets to be safer to consume, healthier, better tasting, and more likely to truly be organic as labeled. 
Additionally, respondents were willing to pay more for organic grape tomatoes sold at these outlets versus those sold at supermarkets or supercenters.

The second tier of organic grape tomatoes were those sold in supermarkets. According to respondents' ratings, these tomatoes were just slightly above average (average ratings ranged from 4.43 to 5.13 on a 7-point scale). They were clearly not perceived to be as high of quality as those in fresh format stores or at farmers markets; however, they were evaluated more favorably than organic grape tomatoes sold in supercenters, which represent the third tier. Participants were only willing to pay $\$ 2.31$ for a pint of organic grape tomatoes from supercenters, on average. Further, participants were most skeptical that the organic grape tomatoes at supercenters would actually be organic. This result lends support to the findings of Ngobo and Jean (2012) in that stores with a low-price emphasis (often the very definition of supercenters) do not necessarily fit well with the overall organic branding strategy.

While the store effect was clearly driving the results in the repeated measures ANOVA models, we observed two instances where other control variables were significant. First, the state variable was significant in the WTP model $(\mathrm{p}=0.0047)$ such that Delaware respondents indicated a higher WTP, on average, than Illinois respondents. This result is not surprising given the significantly higher income of participants in the Delaware sample. Second, we found a significant gender effect $(\mathrm{p}=0.0239)$ in the taste model such that women exhibited higher taste ratings than men, on average. All other control variables had no significant impact on the outcome variables.

\subsection{Effect of Food Safety Information on Willingness to Pay and Safety Perceptions}

The second main objective of this research was to determine how food safety information impacts consumers' WTP and safety perceptions for each retail outlet. Recall that there were two information treatments - the first consisting of just the details of the FSMA and the second with the FSMA information and the specific statement about tomato safety. Table 3 presents the results of these comparisons by retail outlet, state and information treatment.

Considering first WTP, it was hypothesized that bids would: 1) decrease for outlets which consumers perceived as more likely to sell organic grape tomatoes that were exempt from the FSMA (e.g. farmers markets) and 2) increase for outlets which were expected to be less likely to sell FSMA-exempt tomatoes (e.g. supercenters). Before examining the bids, participants' 
expectations about exemptions were checked. On a scale of 1 to 7 with 7 indicating the person thought the organic grape tomatoes at that outlet would be very likely to have been exempt, farmers markets had the highest average rating of 5.20. This was significantly higher than the next outlet believed likely to be exempt, fresh format stores at 4.34. These were the only two with average ratings over the midpoint of the scale. Supermarkets (3.17) and supercenters (3.09) were viewed as unlikely to be selling exempt tomatoes, and both had significantly lower ratings than fresh format stores.

Despite participants' expectations regarding exemptions from the FSMA, there were very few changes in bidding after information was presented. Unexpectedly, there were no significant changes in WTP for any of the retail outlets under either information treatment in Delaware. Instead, bidding was notably consistent with no difference in one instance and differences of only a cent in three other cases. There were similar occurrences of consistent bidding across treatments in Illinois, although there were also two bidding changes that were significantly different. The first, under the FSMA information only treatment, was a \$0.27 decrease in WTP at the farmers market venue ( $\mathrm{p}=0.003)$. The second finding was a decrease of $\$ 0.18$ at fresh format outlets under the FSMA and tomato safety information treatment $(\mathrm{p}=0.074)$. Together, these provide weak evidence of the first part of the hypotheses above. There was no evidence, however, for the second part of the stated hypothesis. It thus appears FSMA information would be of little use to supercenters in terms of increasing consumer WTP.

Essentially the same hypotheses were held for safety rating comparisons and here the results were much different. Both information treatments influenced safety ratings for most of the retail outlets in the direction expected. Looking at these results broadly, it was evident that the provision of safety information helped close the gap in average safety ratings across the retail outlets, particularly for the Illinois sample (pre-information range of safety ratings $=1.85$ and 1.67 for DE and IL, respectively; post-information range of safety ratings $=1.40$ and 0.79 for DE and IL, respectively). The only outlet with no significant differences in ratings was the supermarket. This could be understood in supermarkets being the most popular place for consumers to purchase their produce, so their safety opinion of these outlets is arguably most likely to be set. In contrast, ratings for both farmers markets and fresh format outlets were significantly lower after information in six of the eight instances in the table (all p-values $<0.05$ ). The lone exceptions to the changes were in Delaware under the FSMA information only 
treatment. As noted though, in only two instances did this decrease in safety rating result in a significant decrease in WTP. Supercenters in both states in the FSMA information only treatment saw significant increases in safety ratings. It is uncertain, though, why these increases did not occur in the treatment with tomato safety information added. Perhaps being reminded of how common outbreaks have been gave some participants doubts about the abilities of the FSMA to prevent foodborne illnesses.

\subsection{Other Consumer Perceptions Related to Food Safety}

Beyond evaluating tomatoes from different outlets, participants were also asked about their level of agreement with a series of statements related to food safety and FSMA more broadly. As seen in table 4, among these was the statement that the FSMA would be effective in preventing foodborne illnesses. This statement was the third most agreed with, with an overall average of 3.54. However, the level of agreement with this was significantly lower for the group of participants that had both types of information $(\mathrm{p}=0.0501)$. While this could be evidence of the hypothesis just stated regarding the safety rating of supercenters, more research would be needed on how outbreak details influence consumers' confidence in food safety regulations. None of the other statements had significant differences in level of agreement between the information treatments, and most exhibited almost no difference.

The statement with the highest agreement was that tomato safety was important followed fairly closely by the need for all farms to comply with the FSMA. The latter relates well to the findings above of lower safety ratings for outlets viewed more likely to be exempt. It appears clear from these results that consumers want food safety issues addressed and they think all operations should adhere to the same standards. This was reinforced with the opposition seen to organic farms being exempt from FSMA. Interestingly, and perhaps not surprisingly considering the other statement results, participants did not seem to associate food safety capabilities with farm size, as the average level of agreement landed right near the midpoint of the scale.

\section{Discussion}

This study contributes to the current literature by examining two key issues: (1) whether and how the retail setting impacts perceptions of and WTP for organic products (specifically, organic grape tomatoes), and (2) how information on the proposed FSMA regulations impacts 
safety perceptions and WTP within and across retail outlets. This study also investigates how additional information on tomato food safety alters the influence of the FSMA regulations and whether significant differences exist between an Eastern state (Delaware) where tomato safety outbreaks have been more prevalent and a Midwestern state (Illinois) where outbreaks have been less common.

Results of the study show that the retail setting has a very real impact on consumers' perceptions of and WTP for organic grape tomatoes. Participants in this study rated tomatoes sold in fresh format stores and at farmers markets as better tasting, healthier, and safer than tomatoes sold in supermarkets and supercenters. In addition, participants in both states believed organic grape tomatoes sold in these types of stores were more likely to be truly organic as labeled. While organic grape tomatoes sold in supermarkets and supercenters did not rate as well with consumers as their farmers market and fresh format counterparts, this study showed that the most aversion was toward those sold in supercenters. Respondents rated these tomatoes significantly lower on taste, health, and safety and discounted their WTP values by almost $\$ 1.00$ relative to their farmers market and fresh format bids. These findings are in line with the results of Ngobo and Jean (2012) who concluded that there was a disconnect for consumers when organic brands were sold in stores with a low-price emphasis (e.g., supercenters).

These results are striking in light of the movement of organic to the mainstream. Even though a USDA Organic seal should mean the same thing on a pint of grape tomatoes regardless of where it is sold, this study indicated consumers do not perceive the attributes (taste, health, safety, authenticity) to be equal across retail outlets. This finding is particularly interesting because in both states, the researchers found identical organic grape tomatoes (same brand, same size, same variety) for sale at the supercenter and fresh format stores, yet it is clear one would be dominantly preferred over the other by consumers. Ellison et al. (2016) also find asymmetry in organic evaluations, based on both product type and retail outlet. For the National Organic Program (NOP), this suggests more educational efforts may be needed to increase consumer understanding of organic standards. Alternatively, organic producers may want to be more strategic when choosing a retail outlet, as this choice will likely have impacts on downstream evaluations of their products.

Secondly, results of this study revealed that information on the proposed FSMA regulations impacted safety perceptions yet rarely translated into differences in WTP. For fresh 
format stores and farmers markets, safety ratings significantly decreased in the majority (75\%) of cases; however, a subsequent drop in WTP only occurred in $25 \%$ of cases. For supercenters, on the other hand, safety ratings significantly increased (though only in the FSMA-only information treatment), but this did not coincide with a rise in WTP. These results are consistent with past literature, as several studies have found consumers believe food safety to be important, yet they are only willing to pay a modest premium (10\% or less) for products carrying food safety attributes (Misra, Huang, and Ott, 1991; Latouche, Rainelli, and Vermersch, 1998; Boccaletti and Nardella, 2000; Enneking, 2004).

One explanation for the safety results in the present study may be respondents' aversion to organic grape tomatoes grown by FSMA-exempt farmers, which respondents believed to be most prevalent at farmers markets and fresh format stores and least prevalent at supermarkets and supercenters. The lack of response in WTP values suggests there were desirable (or undesirable) attributes beyond safety that consumers considered and associated with organic tomatoes sold in these retail outlets, and those attributes were strong enough to sustain higher (lower) WTP values. ${ }^{8}$

When looking at preferences for safety overall, the results of this study are consistent with previous studies (Misra, Huang, and Ott, 1991; Lusk and Briggeman, 2009; Ellison and Lusk, 2011). Respondents strongly agreed with the importance of food safety as it pertains to tomatoes and believe all farms - regardless of size or organic status - should be compliant with FSMA regulations. However, confidence in the effectiveness of the proposed FSMA regulations was more tempered. This could be due to the increased attention to and coverage of foodborne illness outbreaks in the media (Frewer, Miles, and Marsh, 2002).

\subsection{Limitations and Areas for Future Research}

While the researchers collected data in two diverse regions of the U.S., there remain potential issues in how generalizable the results are. Both samples (particularly Delaware) had high average incomes and were relatively well educated which could have impacted perceptions and WTP values. Looking forward, researchers could seek to obtain larger, more representative

\footnotetext{
${ }^{8}$ To further examine what might be driving WTP values, we ran additional models that included socio-demographic variables including gender, age, income, education, and state as well as the ratings for taste, health, safety, and confidence. Beyond the effects of store and state already discussed in the text, we found that only taste and confidence ratings were significantly related to WTP values.
} 
samples which encompass all geographic regions of the U.S. Another extension would be to expand upon the products examined as this study only considered one. Retail outlet may exert less influence when non-organic or non-fresh (processed) products are being considered, so a variety of products should be examined in future studies. Related to this, it may be useful to compare premiums for organic products (relative to non-organic) across the different retail outlets. The magnitude of such premiums could vary in ways different than those relationships discovered here. Additionally, future research may want to consider the reputations and images of individual stores within a broad store category (e.g., supercenters, supermarkets). Finally, more effort should also be made in looking at the FSMA and how its shapes consumer opinions and attitudes toward food safety, especially as its policies take effect.

\subsection{Conclusion}

The current literature on organics has primarily focused on identifying consumers' perceptions of organic products and whether (and how much) consumers are willing to pay for those products. The literature has failed to investigate, however, the impact of the purchasing venue on preferences and WTP values - a gap the present study aims to address. This study reveals that the organic label is not perceived uniformly across retail outlets. Rather, organic tomatoes sold in fresh format stores and at farmers markets reaped the most benefits from carrying the organic label (in terms of higher consumer perception ratings and WTP values) whereas organic tomatoes sold in supercenters were viewed less favorably on all measures. It should be pointed out, though, that organic tomatoes sold in supercenters may still be preferred to their non-organic counterparts, so carrying the organic label may still be valuable in these retail settings.

This study also contributes to the food safety literature by determining how information on the newly-proposed FSMA regulations impacts safety perceptions and WTP. Interestingly, the information often affected safety ratings, but rarely influenced WTP values. While safety is an important attribute in consumers' food decisions, it is only one of several factors consumers consider in the valuation process. The significance of the change in safety ratings, though, suggests it might not take too many food safety scares at FSMA-exempt locations for WTP to be influenced. 


\section{Acknowledgements}

This research project is part of Regional Project S-1050: Assessing the Consumer Behavior, Market Coordination and Performance of the Consumer-Oriented Fruit and Vegetable Sector and was partially funded by USDA NIFA \#ILLU-470-356. The authors wish to thank Nicole Wagner, Pam Heinrichs, and Mary Christoph for help running the experiments. 


\section{References}

Angulo, A. M. \& Gil, J. M. (2007). Risk perception and consumer willingness to pay for certified beef in Spain. Food Quality and Preference, 18(8), 1106-1117.

Baker, G. A. (1999). Consumer preferences for food safety attributes in fresh apples: market segments, consumer characteristics, and marketing opportunities. Journal of Agricultural and Resource Economics, 24(1), 80-97.

Becker, G. M., DeGroot, M. H., \& Marschak, J. (1964). Measuring utility by a single-response sequential method. Behavioral Science, 9(3), 226-232.

Boccaletti, S., \& Nardella, M. (2000). Consumer willingness to pay for pesticide-free fresh fruit and vegetables in Italy. The International Food and Agribusiness Management Review, 3(3), 297-310.

Centers for Disease Control and Prevention (CDC). (2014). Estimates of foodborne illness in the United States. Retrieved from http://www.cdc.gov/foodborneburden/\#.

Centers for Disease Control and Prevention (CDC). (2015). List of selected multistate foodborne outbreak investigations. Retrieved from http://www.cdc.gov/foodsafety/outbreaks/multistate-outbreaks/outbreaks-list.html.

Costa-Font, M., Gil, J. M., \& Traill, W. B. (2008). Consumer acceptance, valuation of and attitudes towards genetically modified food: review and implications for food policy. Food Policy, 33(2), 99-111.

Corrigan, J. R. \& Rousu, M. C. (2008). Testing whether field auction experiments are demand revealing in practice. Journal of Agricultural and Resource Economics, 33(2), 290-301.

Economic Research Service (ERS). (2014). Organic market overview. Retrieved from http://www.ers.usda.gov/topics/natural-resources-environment/organicagriculture/organic-market-overview.aspx\#.U8VaZ_ldXzg.

Ellison, B., Duff, B. R. L., Wang, Z., \& White, T.B. (2016). Putting the organic label in context: examining the interactions between the organic label, product type, and retail outlet. Food Quality and Preference, 49, 140-150.

Ellison, B. \& Lusk, J.L. (2011). Taxpayer preferences for USDA expenditures. Choices, Retrieved from http://www.choicesmagazine.org/choices-magazine/submittedarticles/taxpayer-preferences-for-usda-expenditures. 
Enneking, U. (2004). Willingness-to-pay for safety improvements in the German meat sector: the case of the Q\&S label. European Review of Agricultural Economics, 31(2):205-223.

Ewoldt, J. (2013, January 29). Aldi jumps on the organic bandwagon. Star Tribune, Retrieved from http://www.startribune.com/business/188943181.html.

Food and Drug Administration (FDA). (2013). Standards for the growing, harvesting, packing, and holding of produce for human consumption; proposed rule. Retrieved from http://www.fda.gov/downloads/Food/GuidanceRegulation/FSMA/UCM360734.pdf.

Food and Drug Administration (FDA). (2015a). Fact sheets \& presentations. Retrieved from http://www.fda.gov/Food/GuidanceRegulation/FSMA/ucm247546.htm.

Food and Drug Administration (FDA). (2015b). FDA releases groundbreaking rules on produce and imported foods to modernize and strengthen food safety system. Retrieved from http://www.fda.gov/Food/NewsEvents/ConstituentUpdates/ucm472505.htm.

Food and Drug Administration (FDA). (2015c). FSMA final rule on produce safety. Retrieved from http://www.fda.gov/Food/GuidanceRegulation/FSMA/ucm334114.htm.

Frewer, L. J., Miles, S., \& Marsh, R. (2002). The media and genetically modified foods: evidence in support of social amplification of risk. Risk Analysis, 22(4), 701-711.

Harrison, G. W., \& List, J. A. (2004). Field experiments. Journal of Economic Literature, 42(4), 1009-1055.

Henson, S. (1996). Consumer willingness to pay for reductions in the risk of food poisoning in the UK. Journal of Agricultural Economics, 47(3), 403-420.

Hughner, R. S., McDonagh, P., Prothero, A., Shultz II, C. J., \& Stanton, J. (2007). Who are organic food consumers? A compilation and review of why people purchase organic food. Journal of Consumer Behavior, 6(2-3), 94-110.

Latouche, K., Rainelli, P., \& Vermersch, D. (1998). Food safety issues and the BSE scare: some lessons from the French case. Food Policy, 23(5), 347-356.

Lourerio, M. L., \& Umberger, W. J. (2007). A choice experiment model for beef: what US consumer responses tell us about relative preferences for food safety, country-of-origin labeling and traceability. Food Policy, 32(4), 496-514.

Lusk, J. L., \& Briggeman, B. C. (2009). Food values. American Journal of Agricultural Economics, 91(1), 184-196. 
Lusk, J. L., Brown, J., Mark, T., Proseku, I., Thompson, R., \& Welsh, J. (2006). Consumer behavior, public policy, and country-of-origin labeling. Applied Economic Perspectives and Policy, 28(2), 284-292.

Lusk, J. L., Feldkamp, T., \& Schroeder, T. C. (2004). Experimental auction procedure: impact on valuation of quality differentiated goods. American Journal of Agricultural Economics, 86(2), 389-405.

Lusk, J. L., \& Fox, J. A. (2003). Value elicitation in retail and laboratory environments. Economics Letters, 79(1), 27-34.

McCluskey, J. J., Grimsrud, K., Ouchi, H., \& Wahl, T. (2005). Bovine spongiform encephalopathy in Japan: consumers' food safety perceptions and willingness to pay for tested beef. Australian Journal of Agricultural and Resource Economics, 49(2), 197-209.

Misra, S. K., Huang, C. L., \& Ott, S. L. (1991). Consumer willingness to pay for pesticide-free fresh produce. Western Journal of Agricultural Economics, 16(2), 218-227.

Ngobo, P. V., \& Jean, S. (2012). Does store image influence demand for organic store brands? Journal of Retailing and Consumer Services, 19, 621-628.

Onken, K. A., Bernard, J. C., \& Pesek, Jr., J. D. (2011). Comparing willingness to pay for organic, natural, locally grown, and state marketing program promoted foods in the MidAtlantic region. Agricultural and Resource Economics Review, 40(1), 33-47.

Rödiger, M., \& Hamm, U. (2015). How are organic food prices affecting consumer behavior? A review. Food Quality and Preference, 43, 10-20.

Satran, J. (2012, November 20). Food Safety Modernization Act could finally be implemented with election over. Huffington Post, Retrieved from http://www.huffingtonpost.com/2012/11/20/food-safety-modernizationact_n_2147052.html.

Satran, J. (2013, January 4). FSMA regulations on produce, manufactured food finally released for public comment." Huffington Post, Retrieved from http://www.huffingtonpost.com/2013/01/04/fsma-regulations_n_2410456.html.

Thrasher, J. F., Rousu, M. C., Hammond, D., Navarro, A., \& Corrigan, J. R. (2011). Estimating the impact of pictorial health warnings and 'plain' cigarette packaging: evidence from experimental auctions among adult smokers in the United States. Health Policy, 102, 4148. 
Tuttle, B. (2013, June 11). The rise of the swanky no-name brand. Time, Retrieved from http://business.time.com/2013/06/11/the-rise-of-the-swanky-no-name-brand/.

Wohl, J. (2014, April 10). Wal-Mart aims to push organic foods into mainstream. Chicago Tribune, Retrieved from http://articles.chicagotribune.com/2014-04-10/business/ctwalmart-organic-wildoats-0410-biz-20140410_1_wild-oats-organic-groceries-plumorganics.

Worstall, T. (2014, April 10). Maybe Walmart has just killed the organic food market. Forbes, Retrieved from http://www.forbes.com/sites/timworstall/2014/04/10/maybe-walmart-hasjust-killed-the-organic-food-market/. 


\section{Fact Sheet:}

\section{Food Safety Modernization Act (FSMA) Basics:}

Objective: Keep the US food system safe from contamination by preventing it, rather than responding to outbreaks.

\section{Food facilities are required to:}

- Evaluate hazards

- Implement and monitor effective measures preventing contamination

- Have pre-made plan for corrective actions that must be taken

\section{Exemption/Exclusion Rules:}

- Farms with an average of less than $\$ 25,000$ in annual food sales

- Farms with an average of less than $\$ 500,000$ in annual food sales and the majority of food is sold directly to the final consumer or restaurant/retail food establishment located in the same state as the farm or less than 275 miles away

\section{Tomato Safety Quote:}

"From 1973 to 2010, there were 15 multistate outbreaks of illnesses attributed

to Salmonella contamination of raw tomatoes, with 12 of these outbreaks taking place since 2000 . They resulted in almost 2,000 confirmed illnesses and three deaths, with states in the eastern U.S. hardest hit."

--U. S. Food and Drug Administration

Figure 1. Sample Information Treatment

(NOTE: Information treatment 1 only received the FSMA basics section while information treatment 2 received the tomato safety quote in addition to the FSMA basics.) 
Table 1. Characteristics of Study Participants and Definition of Variables $(N=207)$

\begin{tabular}{|c|c|c|}
\hline Variable & Definition & $\begin{array}{c}\text { Sample } \\
\text { Mean or } \\
\text { Proportion }\end{array}$ \\
\hline \multirow[t]{2}{*}{ Gender } & Female & $68.1 \%$ \\
\hline & Male & $31.9 \%$ \\
\hline \multirow[t]{3}{*}{ Education } & High School Diploma/GED & $29.6 \%$ \\
\hline & Bachelor's Degree & $29.1 \%$ \\
\hline & Graduate or Professional Degree & $41.3 \%$ \\
\hline Age & Average age in years & 38.2 \\
\hline Income & Average Annual household income in $\$ 1000$ s & 70.4 \\
\hline \multirow{2}{*}{ Geographic Location } & Delaware & $47.3 \%$ \\
\hline & Illinois & $52.7 \%$ \\
\hline \multirow[t]{2}{*}{ Children in Home } & Yes, children under 18 in household & $19.8 \%$ \\
\hline & No children under 18 in household & $80.2 \%$ \\
\hline \multirow[t]{3}{*}{ Organic Buyer } & Purchases organic produce always or often & $32.4 \%$ \\
\hline & Purchases organic produce sometimes & $57.4 \%$ \\
\hline & Purchases organic produce never & $10.3 \%$ \\
\hline Produce Shopping & Purchases produce at supermarkets always or often & $75.5 \%$ \\
\hline \multirow[t]{11}{*}{ Location } & Purchases produce at supermarkets sometimes & $19.1 \%$ \\
\hline & Purchases produce at supermarkets never & $5.4 \%$ \\
\hline & Purchases produce at supercenters always or often & $37.6 \%$ \\
\hline & Purchases produce at supercenters sometimes & $28.2 \%$ \\
\hline & Purchases produce at supercenters never & $34.2 \%$ \\
\hline & Purchases produce at farmers markets always or often & $55.5 \%$ \\
\hline & Purchases produce at farmers markets sometimes & $30.2 \%$ \\
\hline & Purchases produce at farmers markets never & $14.4 \%$ \\
\hline & Purchases produce at fresh format stores always or often & $33.2 \%$ \\
\hline & Purchases produce at fresh format stores sometimes & $31.2 \%$ \\
\hline & Purchases produce at fresh format stores never & $35.6 \%$ \\
\hline
\end{tabular}


Table 2. Average Consumer Perceptions of and Willingness to Pay (WTP) for Organic Grape Tomatoes by Retail Outlet

\begin{tabular}{|c|c|c|c|c|c|}
\hline Retail Outlet & $\begin{array}{c}\text { Safety } \\
\text { Rating } \\
(\text { Pre-Info })\end{array}$ & $\begin{array}{l}\text { Health } \\
\text { Rating }\end{array}$ & $\begin{array}{c}\text { Taste } \\
\text { Rating }\end{array}$ & $\begin{array}{c}\text { Confidence } \\
\text { Rating }^{\dagger^{*}}\end{array}$ & $\begin{array}{c}\text { WTP } \\
(\text { Pre-Info })\end{array}$ \\
\hline Fresh Format & $\begin{array}{c}5.99^{a} \\
(0.08)\end{array}$ & $\begin{array}{c}6.11^{\mathrm{a}} \\
(0.07)\end{array}$ & $\begin{array}{l}6.10^{b} \\
(0.07)\end{array}$ & $\begin{array}{l}5.81^{a} \\
(0.09)\end{array}$ & $\begin{array}{l}\$ 3.25^{\mathrm{a}} \\
(0.08)\end{array}$ \\
\hline Farmers Market & $\begin{array}{c}5.81^{\mathrm{a}} \\
(0.08)\end{array}$ & $\begin{array}{c}6.13^{\mathrm{a}} \\
(0.06)\end{array}$ & $\begin{array}{l}6.34^{\mathrm{a}} \\
(0.07)\end{array}$ & $\begin{array}{c}5.76^{\mathrm{a}} \\
(0.09)\end{array}$ & $\begin{array}{l}\$ 3.19^{\mathrm{a}} \\
(0.08)\end{array}$ \\
\hline Supermarket & $\begin{array}{l}5.13^{b} \\
(0.09)\end{array}$ & $\begin{array}{l}5.13^{b} \\
(0.09)\end{array}$ & $\begin{array}{l}4.79^{c} \\
(0.09)\end{array}$ & $\begin{array}{l}4.43^{b} \\
(0.12)\end{array}$ & $\begin{array}{l}\$ 2.72^{b} \\
(0.07)\end{array}$ \\
\hline Supercenter & $\begin{array}{l}4.53^{c} \\
(0.11)\end{array}$ & $\begin{array}{l}4.75^{c} \\
(0.11)\end{array}$ & $\begin{array}{l}4.39^{d} \\
(0.10)\end{array}$ & $\begin{array}{l}4.05^{c} \\
(0.13)\end{array}$ & $\begin{array}{l}\$ 2.31^{c} \\
(0.07)\end{array}$ \\
\hline
\end{tabular}

NOTE: Standard errors in parentheses. Averages with the same letter in a column are not significantly different at the 5\% significance level (determined using a repeated measures ANOVA test with Bonferroni corrections for multiple comparisons).

*All ratings were measured on a 7-point scale where 1=Very Unsafe (Very Unhealthy, Tastes Very Bad, No Confidence) and 7=Very Safe (Very Healthy, Tastes Very Good, Complete Confidence).

$\dagger$ Confidence rating refers to how confident participants were that the grape tomatoes labeled as organic are truly organic. 
Table 3. Average Consumer Willingness to Pay (WTP) and Safety Ratings for Organic Grape Tomatoes by Retail Outlet, State and Information Treatment

\begin{tabular}{|c|c|c|c|c|c|c|c|c|}
\hline \multirow[b]{2}{*}{ Information } & \multirow[b]{2}{*}{ State } & \multirow[b]{2}{*}{ Retail Outlet } & \multicolumn{3}{|c|}{ WTP Comparison } & \multicolumn{3}{|c|}{ Safety Rating* Comparison } \\
\hline & & & Pre-Info & Post-Info & $p$-value $e^{\dagger}$ & Pre-Info & Post-Info & $p$-value \\
\hline \multicolumn{9}{|c|}{ Treatment 1 - FSMA Only } \\
\hline \multirow[t]{4}{*}{ (33 obs) } & Delaware & Fresh Format & $\$ 3.45(0.20)$ & $\$ 3.46(0.21)$ & 0.949 & $6.09(0.18)$ & $5.88(0.17)$ & 0.247 \\
\hline & & Farmers Market & $\$ 3.23(0.22)$ & $\$ 3.51(0.18)$ & 0.184 & $5.88(0.22)$ & $5.64(0.18)$ & 0.227 \\
\hline & & Supermarket & $\$ 3.07(0.19)$ & $\$ 3.06(0.19)$ & 0.831 & $4.91(0.24)$ & $5.06(0.23)$ & 0.498 \\
\hline & & Supercenter & $\$ 2.22(0.23)$ & $\$ 2.31(0.24)$ & 0.628 & $4.24(0.27)$ & $4.79(0.22)$ & 0.020 \\
\hline \multirow[t]{4}{*}{$(57 \mathrm{obs})$} & Illinois & Fresh Format & $\$ 3.07(0.15)$ & $\$ 2.97(0.14)$ & 0.328 & $5.88(0.16)$ & $5.56(0.16)$ & 0.045 \\
\hline & & Farmers Market & $\$ 3.03(0.16)$ & $\$ 2.76(0.14)$ & 0.003 & $5.86(0.16)$ & $5.16(0.21)$ & 0.001 \\
\hline & & Supermarket & $\$ 2.50(0.12)$ & $\$ 2.55(0.11)$ & 0.384 & $5.12(0.18)$ & $5.25(0.16)$ & 0.628 \\
\hline & & Supercenter & $\$ 2.19(0.11)$ & $\$ 2.20(0.11)$ & 0.986 & $4.35(0.22)$ & $4.86(0.19)$ & 0.021 \\
\hline \multicolumn{9}{|c|}{ Treatment 2 - FSMA+Tomato Safety } \\
\hline \multirow[t]{4}{*}{$(65$ obs) } & Delaware & Fresh Format & $\$ 3.57(0.13)$ & $\$ 3.56(0.14)$ & 0.949 & $5.80(0.12)$ & $5.48(0.15)$ & 0.037 \\
\hline & & Farmers Market & $\$ 3.41(0.14)$ & $\$ 3.35(0.15)$ & 0.432 & $5.34(0.14)$ & $4.94(0.15)$ & 0.006 \\
\hline & & Supermarket & $\$ 3.01(0.14)$ & $\$ 2.95(0.13)$ & 0.721 & $5.08(0.16)$ & $4.91(0.16)$ & 0.165 \\
\hline & & Supercenter & $\$ 2.61(0.14)$ & $\$ 2.61(0.15)$ & 0.401 & $4.45(0.20)$ & $4.48(0.17)$ & 0.839 \\
\hline \multirow[t]{4}{*}{ (52 obs) } & Illinois & Fresh Format & $\$ 3.10(0.14)$ & $\$ 2.92(0.15)$ & 0.074 & $5.98(0.15)$ & $5.60(0.15)$ & 0.003 \\
\hline & & Farmers Market & $\$ 3.23(0.15)$ & $\$ 3.15(0.15)$ & 0.158 & $6.02(0.14)$ & $5.37(0.19)$ & 0.000 \\
\hline & & Supermarket & $\$ 2.56(0.13)$ & $\$ 2.56(0.13)$ & 0.790 & $5.06(0.19)$ & $5.16(0.18)$ & 0.891 \\
\hline & & Supercenter & $\$ 2.31(0.13)$ & $\$ 2.35(0.14)$ & 0.750 & $4.73(0.23)$ & $4.81(0.22)$ & 0.844 \\
\hline
\end{tabular}

*Safety ratings were measured on a 7-point scale where 1=Very Unsafe and 7=Very Safe

${ }^{\top} \mathrm{P}$-value obtained from Wilcoxon signed rank test for each comparison. 
Table 4. Average Consumer Attitudes Toward Food Safety

\begin{tabular}{lc}
\hline Statement & ${\text { Level of } \text { Agreement }^{*}}^{*}$ Tomato safety is an important concern to address \\
All farms should comply with FSMA regulations. & $4.30(0.06)$ \\
The FSMA will be effective at preventing food illnesses. & $4.09(0.08)$ \\
Small farms are better at food safety than large ones. & $3.54(0.07)$ \\
Organic farms should be exempt from FSMA. & $2.96(0.08)$ \\
\hline
\end{tabular}

NOTE: Standard errors are in parentheses.

*Level of agreement/disagreement was measured on a 5-point scale where 1=Strongly Disagree and 5=Strongly Agree. 


\section{APPENDIX}

(Would like appendix materials to be accessible online) 


\section{Auction Round 1}

Please indicate the price (bid) you would be willing to pay for a pint of organic grape tomatoes from each of the following outlets. Your bid must fall between $\mathbf{\$ 0}$ and $\$ 5$.

Note that your best strategy in this auction is to enter a bid equal to the amount you are actually willing to pay. Please do not just enter how much you think the tomatoes would cost at that location.

Supermarket (e.g. ACME, ShopRite)

$\$$

Farmers Market

$\$$

Supercenter (e.g. Walmart, Target)

$\$$

Fresh Format (e.g. Whole Foods, Fresh Market)

$\$$ 
Section 1: For the following questions, please circle the appropriate number on the scales.

1. Rate each food outlet in terms of how safe you consider their organic grape tomatoes.

\begin{tabular}{lccccccc}
\multicolumn{9}{c}{ Very Unsafe } & & \multicolumn{3}{c}{ Very Safe } \\
Supermarket & 1 & 2 & 3 & 4 & 5 & 6 & 7 \\
Farmers Market & 1 & 2 & 3 & 4 & 5 & 6 & 7 \\
Supercenter & 1 & 2 & 3 & 4 & 5 & 6 & 7 \\
Fresh Format & 1 & 2 & 3 & 4 & 5 & 6 & 7
\end{tabular}

2. Rate each food outlet in terms of how healthy you consider their organic grape tomatoes.

\begin{tabular}{lrrrrrrr}
\multicolumn{3}{c}{ Very Unhealthy } & \multicolumn{4}{c}{ Very Healthy } \\
Supermarket & 1 & 2 & 3 & 4 & 5 & 6 & 7 \\
Farmers Market & 1 & 2 & 3 & 4 & 5 & 6 & 7 \\
Supercenter & 1 & 2 & 3 & 4 & 5 & 6 & 7 \\
Fresh Format & 1 & 2 & 3 & 4 & 5 & 6 & 7
\end{tabular}

3. Rate each food outlet in terms of how you expect the organic grape tomatoes to taste.

\begin{tabular}{lccccccc} 
& Very Bad & & & \multicolumn{3}{c}{ Very Good } \\
Supermarket & 1 & 2 & 3 & 4 & 5 & 6 & 7 \\
Farmers Market & 1 & 2 & 3 & 4 & 5 & 6 & 7 \\
Supercenter & 1 & 2 & 3 & 4 & 5 & 6 & 7 \\
Fresh Format & 1 & 2 & 3 & 4 & 5 & 6 & 7
\end{tabular}

4. Rate each food outlet in terms of how confident you are that the grape tomatoes labeled as organic are truly organic.

\begin{tabular}{lccccccc}
\multicolumn{3}{c}{ No Confidence } & \multicolumn{4}{c}{ Completely Confident } \\
Supermarket & 1 & 2 & 3 & 4 & 5 & 6 & 7 \\
Farmers Market & 1 & 2 & 3 & 4 & 5 & 6 & 7 \\
Supercenter & 1 & 2 & 3 & 4 & 5 & 6 & 7 \\
Fresh Format & 1 & 2 & 3 & 4 & 5 & 6 & 7
\end{tabular}

*Please flip page to complete this section* 
5. For each outlet, rate how you believe the safety of their organic version compares to their conventional version.

\begin{tabular}{lccccccc}
\multicolumn{1}{c}{$\begin{array}{c}\text { Organic Much } \\
\text { Less Safe }\end{array}$} & \multicolumn{3}{c}{ No } & \multicolumn{2}{c}{$\begin{array}{c}\text { Organic Much } \\
\text { Difference } \\
\text { More Safe }\end{array}$} \\
Supermarket & 1 & 2 & 3 & 4 & 5 & 6 & 7 \\
Farmers Market & 1 & 2 & 3 & 4 & 5 & 6 & 7 \\
Supercenter & 1 & 2 & 3 & 4 & 5 & 6 & 7 \\
Fresh Format & 1 & 2 & 3 & 4 & 5 & 6 & 7
\end{tabular}

6. For each outlet, rate how you believe the healthiness of their organic version compares to their conventional version.

\begin{tabular}{lccccccc} 
& \multicolumn{3}{c}{ Organic Much } & \multicolumn{3}{c}{ No } & \multicolumn{2}{c}{$\begin{array}{c}\text { Organic Much } \\
\text { Less Healthy }\end{array}$} \\
Supermarket & 1 & 2 & 3 & 4 & 5 & 6 & 7 \\
Farmers Market & 1 & 2 & 3 & 4 & 5 & 6 & 7 \\
Supercenter & 1 & 2 & 3 & 4 & 5 & 6 & 7 \\
Fresh Format & 1 & 2 & 3 & 4 & 5 & 6 & 7
\end{tabular}

7. For each outlet, rate how you believe the taste of their organic version compares to their conventional version.

\begin{tabular}{lccccccc} 
& \multicolumn{3}{c}{$\begin{array}{c}\text { Organic Tastes } \\
\text { Much Worse }\end{array}$} & \multicolumn{3}{c}{ Difference } & \multicolumn{2}{c}{$\begin{array}{c}\text { Organic Tastes } \\
\text { Much Better }\end{array}$} \\
Supermarket & 1 & 2 & 3 & 4 & 5 & 6 & 7 \\
Farmers Market & 1 & 2 & 3 & 4 & 5 & 6 & 7 \\
Supercenter & 1 & 2 & 3 & 4 & 5 & 6 & 7 \\
Fresh Format & 1 & 2 & 3 & 4 & 5 & 6 & 7
\end{tabular}

8. Rate your knowledge of the following topics.

No Knowledge

Very Knowledgeable

$\begin{array}{llllllll}\text { Food Safety Modernization Act (FSMA) } & 1 & 2 & 3 & 4 & 5 & 6 & 7 \\ \text { Organic } & 1 & 2 & 3 & 4 & 5 & 6 & 7 \\ \text { Tomato safety } & 1 & 2 & 3 & 4 & 5 & 6 & 7 \\ \text { Salmonella } & 1 & 2 & 3 & 4 & 5 & 6 & 7\end{array}$

You have completed the first section.

Please exchange this section for an information sheet to continue. 


\section{Auction Round 2}

Please indicate the price (bid) you would be willing to pay for a pint of organic grape tomatoes from each of the following outlets. Your bid must fall between $\$ 0$ and $\$ 5$.

Again, note that your best strategy in this auction is to enter a bid equal to the amount you are actually willing to pay. Please do not just enter how much you think the tomatoes would cost at that location.

Supermarket (e.g. ACME, ShopRite)

$\$$

Farmers Market

$\$$

Supercenter (e.g. Walmart, Target)

$\$$

Fresh Format (e.g. Whole Foods, Fresh Market)

$\$$ 
Section 2: For these questions, please circle the appropriate number on the rating scales.

1. Please read the following statements and choose to what degree you agree or disagree.

\begin{tabular}{|c|c|c|c|c|c|}
\hline \multirow[b]{2}{*}{ All farms should comply with FSMA regulations. } & \multicolumn{2}{|c|}{$\begin{array}{l}\text { Strongly } \\
\text { Disagree }\end{array}$} & & \multicolumn{2}{|c|}{$\begin{array}{l}\text { Strongly } \\
\text { Agree }\end{array}$} \\
\hline & 1 & 2 & 3 & 4 & 5 \\
\hline Small farms are better at food safety than large ones. & 1 & 2 & 3 & 4 & 5 \\
\hline Tomato safety is an important concern to address. & 1 & 2 & 3 & 4 & 5 \\
\hline Organic farms should be exempt from FSMA. & 1 & 2 & 3 & 4 & 5 \\
\hline e FSMA will be effective at preventing food illne & 1 & 2 & 3 & 4 & 5 \\
\hline
\end{tabular}

2. Rate each food outlet in terms of how safe you consider their organic grape tomatoes.

\begin{tabular}{lccccccc}
\multicolumn{3}{c}{ Very Unsafe } & & \multicolumn{3}{c}{ Very Safe } \\
Supermarket & 1 & 2 & 3 & 4 & 5 & 6 & 7 \\
Farmers Market & 1 & 2 & 3 & 4 & 5 & 6 & 7 \\
Supercenter & 1 & 2 & 3 & 4 & 5 & 6 & 7 \\
Fresh Format & 1 & 2 & 3 & 4 & 5 & 6 & 7
\end{tabular}

3. For each outlet, rate how you believe the safety of their organic version compares to their conventional version.

\begin{tabular}{lccccccc} 
& \multicolumn{3}{c}{$\begin{array}{c}\text { Organic Much } \\
\text { Less Safe }\end{array}$} & \multicolumn{3}{c}{ No } & \multicolumn{2}{c}{ Organic Much } \\
Difference & & \multicolumn{1}{c}{ More Safe } \\
Supermarket & 1 & 2 & 3 & 4 & 5 & 6 & 7 \\
Farmers Market & 1 & 2 & 3 & 4 & 5 & 6 & 7 \\
Supercenter & 1 & 2 & 3 & 4 & 5 & 6 & 7 \\
Fresh Format & 1 & 2 & 3 & 4 & 5 & 6 & 7
\end{tabular}

4. Rate each outlet in terms of how likely they are to sell organic grape tomatoes that are exempt from FSMA.

\begin{tabular}{lccccccc} 
& Very Unlikely & & \multicolumn{3}{c}{ Very Likely } \\
Supermarket & 1 & 2 & 3 & 4 & 5 & 6 & 7 \\
Farmers Market & 1 & 2 & 3 & 4 & 5 & 6 & 7 \\
Supercenter & 1 & 2 & 3 & 4 & 5 & 6 & 7 \\
Fresh Format & 1 & 2 & 3 & 4 & 5 & 6 & 7
\end{tabular}


Section 3: For the following questions, please place a check in front of your answer. Remember this information will remain confidential and is important for the study.

1. What is your gender?

- Male $\quad$ Female

2. What is your age?

\begin{tabular}{|c|c|}
\hline $18-24$ & $25-34$ \\
\hline $45-54$ & $55-64$ \\
\hline
\end{tabular}

3. What ethnicity best describes you?

\begin{tabular}{|c|c|c|}
\hline White & Hispanic/Latino & Black/African American \\
\hline Asian & Other & \\
\hline
\end{tabular}

4. What is your highest level of completed education?

$\begin{array}{ll}\text { Less than high school } & \text { High school } \\ \text { Bachelor's degree } & \text { Graduate or professional degree }\end{array}$

5. Do you have children under 18 in your household?

Yes $\quad$ No

6. Do you work on a farm?

Yes $\quad$ No

7. What is your annual household income?

$\begin{aligned} & \text { Less than } \$ 24,000 \\ & \$ 50,000 \text { to } \$ 74,999\end{aligned}-\begin{aligned} & \$ 25,000 \text { to } \$ 34,999 \\ & \$ 75,000 \text { to } \$ 99,999\end{aligned} \quad \begin{aligned} & \$ 35,000 \text { to } \$ 49,999 \\ & \$ 150,000 \text { to } \$ 199,999\end{aligned}-\$ 100,000$ to $\$ 149,999$

**Please flip page to complete this final survey section** 
8. How often to you purchase fresh produce at each of the following outlets?

\begin{tabular}{lcccc} 
& Never & & \multicolumn{2}{c}{ Always } \\
Supermarket (e.g. ACME, ShopRite) & 1 & 2 & 3 & 4 \\
Farmers Market & 1 & 2 & 3 & 4 \\
Supercenter (e.g. Walmart, Target) & 1 & 2 & 3 & 4 \\
Fresh Format (e.g. Whole Foods, Fresh Market) & 1 & 2 & 3 & 4
\end{tabular}

9. How often do you buy organic produce?

Never

Sometimes

Often

Always

10. Lastly, if you are willing, we would like to give you one organic grape tomato to try. Please select which one you'd like to try:

Supermarket
Farmers Market
Supercenter
Fresh Format
Do not want to try one

11. If you tried one, how did it taste compared to your expectations for that outlet?

\begin{tabular}{|c|c|c|c|c|c|}
\hline Much Worse & & $\mathrm{No}$ & & & Much Better \\
\hline Than Expected & & ffer & & & Than Expected \\
\hline 1 & 3 & 4 & 5 & 6 & 7 \\
\hline
\end{tabular}

Thank you for your participation in this survey. 